\title{
¿Hacia dónde camina la Prehistoria Española?
}

\section{M. ${ }^{a}$ Rosario Lucas Pellicer}

Arbor CLXI, 635-636 (Noviembre-Diciembre 1998), 383-397 pp.

La investigación prehistórica está cargada de novedades que apuntan hacia la generalización de los enfoques actuales. Explicación e interpretación de procesos y cambios, y la idea de que el registro arqueológico (en el amplio concepto de asentamiento humano/territorio) puede darnos muchas respuestas si se saben formular y multiplicar las preguntas y se cuenta con métodos adecuados, guían la investigación futura para trazar una especie de Antropología Prehistórica.

Se incrementará y perfeccionará la analitica de laboratorio y el muestreo, con objeto de conocer mejor el Espacio y su interrelación con la Conducta Humana bajo el prisma del Tiempo.

Se ha perdido la inocencia y se ha ganado optimismo. Esta frase, que alude a conceptos manidos por la huella del tiempo en lo que se ha llamado "Nueva Arqueología", resume la entrada en el futuro de la investigación prehistórica. Interpretación o, mejor aún, explicación y recreación del pasado, y la idea de que el registro arqueológico, en el amplio concepto de asentamiento humano, puede darnos muchas respuestas si se saben formular y multiplicar las preguntas y se cuenta con métodos adecuados, son las bases que guían y orientan la investigación en Prehistoria.

Enfoques culturales íntegros, económicos, sociales e ideológicos, en el sentido de proceso y cambio, son las claves con las que se mira el 
pasado bajo la perspectiva diacrónica. Para el presente importan las actividades didácticas: tanscender los resultados a nivel social.

Antes de proseguir el discurso, una advertencia previa: el contenido de estas páginas se centra prioritariamente en la prehistoria de las sociedades postpaleolíticas - prehistoria reciente y final- aunque la mayoría de los enfoques son compartidos y aplicables a la investigación de las poblaciones plenamente prehistóricas o ágrafas y a las sociedades con escritura. Justamente, el estudio de las sociedades más remotas ha contribuido de una manera eficaz al desarrollo de nuevas estrategias de estudio, y el reto de la mutilada documentación ha sido un acicate para mejorar el registro de campo e impulsar la aplicación de técnicas y procedimientos basados en la cuantificación, la analítica y el estudio del espacio.

Deliberadamente eludo el listado bibliográfico para no incurrir en omisiones de colegas que desde las Universidades, el Consejo o Centros Autonómicos, están trabajando muy positivamente desde hace más de una década, con enfoques teóricos y metodológicos renovados. Valga como referencia la cita de una Revista puntera en estas cuestiones: TRABAJOS DE PREHISTORIA, editada por el Centro de Estudios Históricos del C.S.I.C.

Las fuentes de estas páginas están basadas en mi experiencia profesional y en la serie de títulos de artículos y libros editados en los últimos años, tema y programa de reuniones científicas y especialmente en Memorias de Licenciatura y Tesis Doctorales, reflejo de lo que les interesa a los jóvenes Licencidos y Doctores. Ellos son el futuro generacional.

Poblamiento, Economía, Sociedad, Tecnología, Paleoambiente Arqueometría, Análisis de componentes y Arte/Simbología son, por este orden, los campos más atractivos junto al esfuerzo lento pero imparable de la didáctica 0 , mejor aún, de la preocupación por la proyección social del trabajo de los prehistoriadores.

Como muestra de las nuevas orientaciones valgan las siguientes referencias, tomadas al azar, en un largo elenco de títulos dominados, lógicamente, por temas dedicados a excavaciones concretas o a momentos culturales determinados en un ámbito específico:

"Dinámica del paisaje. Paisajes sociales. Análisis multivariante de la prospección arqueológica. Aspectos geomorfológicos y geoarqueológicos. Dinámica del poblamiento. El agua como poder. Substrato. Paleoetnología. Cambio cultural. Identificación de cadenas operativas. Redes de intercambio. Factores y medios de producción y reproducción. Gestión pluriactiva del ecosistema. Caracterización arqueométrica. Los SIG y el 
¿Hacia dónde camina la Prehistoria española?

Análisis Espacial. Reconstrucción arquitectónica y medioambiental. Análisis de una unidad habitacional..."

La renovación de objetivos ha tenido como efecto una sólida concienciación de las limitaciones interpretativas de la investigación tradicional. Conocidas las lagunas se ha cargado el énfasis en cuestiones que parecían irresolubles $\mathrm{y}$, al calor de unos pocos y por el impacto de convocatorias sobre temas muy específicos, determinados grupos están fomentando ambiciosos objetivos y desarrollando estrategias concretas que, como estímulo, modelo o controversia, dan lugar a la multiplicidad de líneas de investigación persiguiendo los mismos objetivos y ampliando las propuestas.

A nivel académico, el nuevo plan de estudio ha brindado la oportunidad de nuevas asignaturas en la Licenciatura de Historia: $\mathrm{Ar}$ queología Espacial, Paisaje y Patrones de asentamiento, Etnoarqueología, Arqueología Experimental, Tecnología, Traceología, Arqueología de la Muerte, La Mujer en la Prehistoria, "Sistemas de Expertos" en Arqueología, Introduccion a los SIG y su aplicación en Prehistoria, Análisis de los paisajes agrarios, Antracología, Zooarqueología, Paleometalurgia, Símbolos y Arte prehistóricos, Gestión y protección del Patrimonio Arqueológico.... materias impartidas de una manera bastante generalizada por los prehistoriadores con la posibilidad de complementar la formación con ofertas específicas de la especialidad de Antropología o de Facultades de Ciencias: Física y Química de la Cerámica Antigua, Técnicas analíticas al servicio de la Arqueología, Arqueometría, Edafología, ..., asignaturas que no agotan ni mucho menos las tendencias actuales en la formación de Licenciados y Doctores cuyas titulaciones se estrenarán en las postrimerías del siglo XX y a comienzos del siglo XXI.

Pese a que administrativamente se ha cercenado la titulación o especialidad en Prehistoria y/o Arqueología, la formación actual pretende ser un encuentro entre Historia/Antropología Cultural/Etnoarqueología y Ciencias, en el que cabe destacar, por una parte, la incursión de los prehistoriadores en campos especializados que, en principio, se juzgarían como exclusivos de Ciencias; por otra, el interés de los científicos por aplicar la investigación y sus métodos de trabajo al conocimiento del pasado humano, avanzando lentamente en el diálogo entre prehistoriadores y científicos. En una palabra, caminando hacia la investigación interdisciplinaria.

Se está trabajando muy bien en seis enfoques, otras tantas puertas abiertas al porvenir y a las perspectivas del futuro: 
1) Prospección y territorio (énfasis en la geografía y el ambiente, economía, asentamiento, procesos de deposición y registro documental: Arqueología Espacial y Excavación).

2) Contextualización (importancia y potencialidad del registro en sentido natural y humano, asociaciones, sincronía, reconstrucciones y perspectiva diacrónica: Cronología, organización y procesamiento de datos y simulaciones).

3) Tecnología y funcionalidad (materia, elaboración y uso, economía de las poblaciones. Arqueología Experimental y Etnoarqueología).

4) Analítica (interdisciplinariedad de los estudios para ampliar.

y sacar mayor partido a la documentación).

5) Ideología (sociedad, religión, artes y símbolos: Arqueología Simbólica o Congnitiva y Arqueología de la Muerte).

6) Proyección social (Patrimonio/Divulgación).

\section{¿Qué papel ocupan la cultura material y la cronología?}

Obviamente los restos materiales son la base documental y obligada referencia para las clasificaciones culturales, pero el interés se centra menos en la morfología y en la tipología y más en la materia, la técnica, la función, número (cuantificación) y distribución o regresión espacial, a la vez que son punto de partida para recabar las circunstancias que explican la vida humana y su proyección en el pasado.

En cuanto a la cronología, el énfasis recae en obtener una buena cantidad de dataciones y no fechas aisladas. El método por excelencia sigue siendo el Radiocarbono $\left(\mathrm{C}_{14}\right)$. A este respecto, la calibración es un caballo de batalla que causa gran desconcierto por falta de superación mental de los esquemas cronológicos y porque, cuando se trata de interrelaciones espaciales o secuencias temporales amplias, la documentación a manejar no está corregida. La cronología de los últimos años se lee en fechas calibradas ( $c a l$.) mientras las dataciones más antiguas se refieren a BP (before the present: 1950) convertidas en años antes de nuestra era o de Cristo. Además de la Revista Radiocarbon y de las tablas para cálculo de calibraciones, existen distintos programas informáticos capaces de convertir las dataciones en fechas calibradas ${ }^{1}$. Con todo, y este es un aspecto que habrá de cambiarse, en las síntesis de Prehistoria y a nivel de aulas, privan los esquemas de fechas no calibradas. El futuro, obviamente, está en el lenguaje calibrado y en la exigencia cada vez mayor de situaciones temporales afinadas; la fiabilidad al analizar los contextos espaciales y deposicionales, depende, 


\section{¿Hacia dónde camina la Prehistoria española?}

lógicamente, de haber utilizado en las hipótesis y entrecruzamiento de datos situaciones coetáneas. Igualmente, en el análisis de las variables que provocan la dinámica y el cambio de las poblaciones debe tenerse muy en cuenta la temporalidad de los fenómenos. Por esta razón se están multiplicando las propuestas para superar las limitaciones e incrementar el repertorio de fechas: el análisis radiocarbónico por AMS (espectrometría por acelerador de partículas) abre nuevas esperanzas a la datación de muestras minúsculas y es un hecho notorio la eficiencia de esta técnica en la cronología de pigmentos orgánicos paleolíticos, caso de las pinturas de Altamira y otros sitios con Arte rupestre ${ }^{2}$.

Si en su momento la dendrocronología sirvió de guía para corregir errores en tiempo radiocarbónico, lo deseable actualmente es obtener de un mismo contexto fechas por distintos laboratorios y métodos. La termoluminiscencia (TL) cuenta ya en España con cierta veteranía merced al impulso de C. Blasco y a las relaciones entre los Departamentos de Geología y Prehistoria de la UAM, y el futuro está, indudablemente, en la confrontación de dataciones obtenidas por distintos procedimientos. En proceso experimental con gran futuro, cabe destacar la Resonancia Electrónica (ESR) y la Racemización de aminoácidos (restos orgánicos animales) y, en fase inicial, la datación por Rayos iónicos o por Tasa de Cationes (para pátinas de grabados prehistóricos). $\mathrm{Si}$ estos y otros métodos se aplican muy ocasionalmente o aparecen sólo en la bibliografía teórica, es por razones económicas y porque, si se dispone de muestras potenciales, el análisis C14 se ha convertido en rutina.

\section{Teoría y objetivos de la investigación}

Los prehistoriadores españoles, desde inicios de los años 80 , han seguido puntualmente las tendencias difundidas en lengua inglesa y francesesa (esta última especialmente para los enfoques de las sociedades depredadoras) con la ventaja de no quedarse en la epistemología y desarrollar una arqueología de campo y una investigación eminentemente activa en la que la cuantificación y el uso de la informática no han quedado a la zaga. Incluso las críticas entre seguidores de diversas corrientes teóricas y la tradición y formación histórica, han servido de contrapunto a los excesos y han ido imponiendo mayor rigor en métodos y técnicas, modelos y propuestas alternativas. Podríamos decir que se tiende al equilibrio entre las distintas posturas 
(procesual, estructuralista, marxista... en versión "neo» o "post») y a seguir aquellos enfoques y estrategias que más y mejor se adecúan a los objetivos de la investigación, siempre bajo la perspectiva temporal y la inserción en procesos amplios que confieren la verdadera dimensión histórica. Quizás, lo que ha cambiado más radicalmente es el enfoque hacia el pasado humano y el concebir la prehistoria como interrelación de variables dinámicas inherentes a la conducta humana y como causas y parámetros implicados en las particularidades del proceso y en el cambio cultural, siendo muy conscientes de que la investigación arqueológica es la única vía para escribir y comprender la Prehistoria. En este sentido, la discusión sobre nomenclatura de "edades", "períodos", "culturas" etc. ha amainado. El objetivo está en determinar el proceso cultural de los grupos de población, desde la óptica de trayectoria sistémica, y explicar las razones que motivan su comportamiento, poniendo énfasis en el cambio y las causas que propician el estancamiento o la evolución. Consecuentemente se ha ido imponiendo una "jerga" de la que nadie nos vemos libres, tomada de las fuentes que más convienen a los modelos y métodos: Antropología, Matemáticas, Informática y Filosofía de la Ciencia y, también hay que decirlo, llena de anglicismos, fruto de la "traducción" al español de los vocablos ingleses, la lengua de mayor peso. Las jóvenes generaciones sienten un fervor especial por este nuevo lenguaje como distintivo de modernidad y su incursión masiva a nivel oral o de bibliografía prehistórica es ya imparable.

Bajo conceptos tradicionales (caso de asignaturas con títulos de "Edad de...", "Neolítico», "La Peninsula durante tal o cual milenio" o simplemente de Prehistoria o Protohistoria de toda la geográfica o una parcela del territorio) hallaremos un programa de sociedades depredadoras o productoras de determinada complejidad social donde la génesis del substrato, la causalidad que promueve el proceso, los patrones de asentamiento y los aspectos económico y social, siempre bajo el prisma de la moderna antropología, tienen tanto o más peso que la "cultura material".

Estas consideraciones no deben llevar a engaños. Ensanchar y hollar caminos está por venir. Se avanza lentamente y sigue privando la estructura tradicional; aunque se incorporen como parte inexcusable de la publicación las consideraciones económicas y sociales pertinentes, las hipótesis son conjeturas más que probabilidades o teorías contrastadas. Estamos lejos de aclararnos con los modelos de apoyo teórico y escasos de explicaciones satisfactorias, pese a que las estrategias de trabajo son cada vez más complejas y no se marginan los análisis faunísticos, botánicos o de componentes materiales. 


\section{¿Hacia dónde camina la Prehistoria española?}

Llegados a este punto conviene incidir en las dos polos sobre los que gravita la plataforma de la invesigación: el espacio como escenario y el comportamiento como acción del auténtico protagonista: el hombre.

\section{El Espacio}

Tradicionalmente se decía que los ojos de la Historia eran la Cronología y la Geografía. En el caso de la Prehistoria este ojo de la Geografía se integra en el concepto amplio de la Arqueología Espacial y si la cronología atiende a la idea "vertical" de la superposición de estratos, el espacio conlleva la relación "horizontal» de la superficie habitada.

Desde 1984, fecha del primer Coloquio de Arqueología Espacial, que por iniciativa de F. Burillo se celebró en Teruel, ciudad consagrada a estos encuentros, el análisis del espacio acapara las metas de la investigación. Bajo tal denominación se engloban enfoques confluyentes que tienen como denominador común conocer el entorno, el marco físico y ecológico mutable, referente para la vida humana. Se parte de dos corolarios:

1. El análisis arqueológico no puede limitarse al espacio concreto del contexto (estructuras y elementos muebles) ni al concepto tradicional de yacimiento aislado. Se parte de la noción del asentamiento entramado a distintos niveles (micro, meso y macro) y el análisis se enfoca hacia:

a) el modo de utilizar el espacio desde el punto de vista interno (unidades domésticas o segmentos relativos a la producción y a la organización colectiva: vida en acción, es decir hábitat, necrópolis y/o lugares religosos, lo que se entiende comúnmente como unidades explícitas o latentes — evidencias indirectas - en el curso de la vida humana),

b) el área de recursos (explotación del territorio y captación de recursos: uso externo),

c) la posición y el papel del asentamiento (tamaño y rango) en una malla de relaciones geográficas y humanas (redes y categoría de contactos).

2. Es imprescindible conocer el ambiente (condiciones climáticas y ecológicas) del pasado. En este sentido y como estrategias para llegar a 1. interesa:

a) registrar elementos orgánicos e inorgánicos susceptibles de infomación ambiental (paleoecología) y poststdeposicional (formación/trasformación del depósito por causas naturales o humanas), 
b) la disponibilidad de recursos para explicar la explotación selectiva, la intensidad o grado en el sentido de lo que el hombre consumió, produjo o se benefició y las limitaciones o las estrategias adoptadas para paliar carencias y riesgos o intensificar la producción,

c) evaluar el impacto antrópico producido en el paisaje por la presencia y las actividades humanas.

Así pues, la arqueología espacial no se limita al estudio del territorio a escala de área de activdad o de inserción en un contexto regional, sino que exige un enfoque ecológico y ambiental explícito -el ecosistema - y engloba la paleoecología, la reconstrucción del paisaje (la geografía humanizada) contraponiendo los "artefactos" a los "ecofactos" (evidencias de la evolución ecológica) ${ }^{3}$ y por tanto dando nueva dimensión a los tradicionales análisis del suelo (edafológicos y geoquímicos) de la fauna (Arqueozoología) y de la vegetación (Arqueobotánica en sus distintas ramas) hoy prioritariamente interesados por los restos microscópicos y determinadas evidencias localizadas en el laboratorio o extraídas directamente en el campo por flotación y cribado de la tierra: fitolitos, coprolitos, parásitos, bacterias, microorganismos de todo tipo y ausencia, presencia y proporción de elementos tales como grasas, colágeno, estroncio, fosfatos, oligoelementos... La actividad futura incidirá cada vez más en la geomorfología y en el medio ambiente y se ampliarán los métodos de muestreo y la búsqueda de columnas de sedimentos para mejorar la aproximación a la incidencia del clima y el paisaje, la posibilidad de catástrofes naturales y la trasformación del ecosistema como marco de acontecimientos y como vector del cambio cultural.

Por ello, la Arqueología Espacial conecta además con la Etnoarqueología ${ }^{4}$ y con la Arqueología Experimental ${ }^{5}$ como fuentes para desarrollar hipótesis y, por programas informáticos, simular modelos del trascurrir el tiempo y, además, evaluar qué circunstancias naturales han incidido en los procesos postdeposicionales (en este sentido se han abierto nuevas perspectivas para la localización de yacimientos). Tampoco es ajeno a este tipo de enfoques la Arqueología Cognitiva o Simbólica (una de las asignaturas más pendientes, impulsada en España por Felipe Criado, desde los grupos de trabajo de la Universidad de Santiago de Compostela) entendida en este caso como asunción del paisaje natural y humano desde el punto de vista simbólico y su repercusión en la conducta humana (límites y esferas suprahumanas dentro del territorio: la percepción y relación con lo imaginario).

Partiendo de métodos geográficos, el análisis espacial se ha enriquecido con el perfeccionamiento y alternativas a los tradicionales po- 


\section{¿Hacia dónde camina la Prehistoria española?}

lígonos de Thiessen y sobre todo con la aplicación de los SIG (Sistemas de Información Geográfica) una de las más modernas y esperanzadoras herramientas, merced al desarrollo de la cartografía informatizada ${ }^{6}$ y a las posibilidades de entrecruzar e incorporar documentación obtenida por diversos procedimientos fotográficos o icónicos.

\section{El comportamiento humano}

El hombre, o mejor dicho el grupo humano, en su contexto espacial y temporal - la población de un territorio- sigue siendo el gran protagonista y su conducta el objetivo último, sin marginar hechos de largo alcance, convergentes o no, que han marcado la dinámica de los cambios más transcendentales a nivel económico, social e ideológico ( p. e. origen de la domesticación y del cultivo y el ascenso al nivel urbano - las llamadas por G. Childe "revolución neolítica" y "revolución urbana»- bajo nuevos enfoques ligados a fenómenos tales como "la revolución de los productos derivados o secundarios" propugnada por A. Sherratt, el surgimiento de la estratificación o jerarquía social y la marcha hacia el poder o el estado). Se parte de los siguientes asertos, siempre bajo la perspectiva de un sistema complejo y activo, en un ambiente determinado:

1. Todo grupo humano desarrolla una estrategia específica para cubrir sus necesidades como ser vivo, pensante y social: exigencia de hábitat en sentido amplio, alimentación, y atención a las necesidades materiales e ideológicas. Es decir, funcionan unos patrones de asentamiento más o menos estables o itinerantes, y existe un orden económico basado en la explotación y producción de recursos y materias primas -organización y mecanismos de la cadena producción/consumo/función/reproducción - de acuerdo a una determinada tecnología, involucrando las relaciones sociales bajo determinada ideología y mentalidad. Todo ello conectado con el espacio y el trascurso del tiempo.

2. La organización social abarca las relaciones primarias (domésticas o familiares) y comunales y es preciso conocer la demografía de la población y el grado y complejidad (diferencias por sexo y edad, igualdad o estratificación social, estatus, rango y poder) y las estrategias para mantener y reproducir el sistema, así como la interdependencia con la economía y el universo conceptual.

También se contemplan dentro de este polo las relaciones respecto a otras comunidades coetáneas (límites cerrados o permeables, orga- 
nización jerarquizada o no del territorio, lugar central, alianzas..., modos de comunicación y redes de intercambio).

En esta esfera del hombre como individuo y miembro social hay una línea en marcha que en un futuro muy próximo ampliará los análisis antropológicos e incidirá fuertemente en la interpretación social. Me refiero al ser vivo como tal y a las contingencias demográficas. Se avanzará en la dieta, nutrición y patologías y se llegará a concer el aspecto físico (merced a las técnicas utilizadas actualmente por la medicina forense), incluyendo huellas dactilares (presentes en la cerámica, pintura digital, improntas...), parentesco y consanguinidad (análisis de $\mathrm{ADN}$ )... Algo que parece ciencia-ficción, que en principio se almacenará en bancos de datos como otros muchos resultados de muestreos, en espera de mayores evidencias e interrelaciones, será parte de las futuras interpretaciones relacionadas con la biología y la $\mathrm{Ar}$ queología de la Muerte, y ayudarán a esclarecer problemas actualmente tan controvertidos como endogamias/exogamias, migraciones, invasiones, autoctonías, mestizajes... o la inclusión del parámetro salubridad, endemias o pandemias en la explicación del cambio cultural.

Aquí cabe añadir el movimiento (principalmente desde la Universidad Autónoma de Barcelona) de una Arqueología Femenina. En mi opinión, lo que más importa es el impulso de los estudios sobre el lugar y repercusión de la mujer, complementando la perspectiva social $\mathrm{y}$ atenuando el androcentrismo que ha privado en Prehistoria.

3. Las creencias, las ideas y la capacidad simbólica, o si se quiere la dimensión ontológica, forman parte inherente del funcionamiento cultural. La Muerte (necrópolis, ajuares y ritos) y el Arte son hoy en día las mejores fuentes, unidas a la búsqueda de centros o lugares carismáticos que catalizan las creencias y las relaciones sociales, y a cuantos elementos reales o latentes traducen la mentalidad del grupo y su incidencia en lo social: los llamados sociofactos que, por rareza de la materia, elaboración, reiteración o función en determinados contextos, actúan de "marcadores sociales" y encierran un valor primario o intrínseco añadido al valor material.

Están por desarrollar (intentos muy puntuales) vías de trabajo que lleven hacia unidades de medida y de valor y, en general, a los sistemas simbólicos de identidad grupal, comunicación/información visual y oral. Es bueno reconocer que se ha dado un paso adelante, al menos en los intentos por rastrear la etnicidad de las poblaciones de la prehistoria final, y en el acercamiento entre prehistoriadores y lingüistas a la búsqueda del substrato y ramas de un lengüaje común o diferenciado. La presencia de estos estudios en la bibliografía y de los propios lin- 


\section{¿Hacia dónde camina la Prehistoria española?}

güistas en las reuniones sobre Prehistoria Final dice mucho del interés mútuo en resolver problemas.

\section{La proyección social}

Digamos que a nivel de publicaciones el futuro es alentador y el ordenador una herramienta imprescindible que traerá la biblioteca de novedades a la mesa del despacho. Pero se impone además la exigencia de difundir la investigación prehistórica a niveles más amplios y la necesidad de conservar los yacimientos. Si toda excavación es destructiva, en la Prehistoria el drama se agrava por la dolencia de monumentalidad y las dificultades de conservar (caso de que exista tal política). Contra cualquier desaliento, el prehistoriador tiene una clara voluntad de llegar a todos. Reconstrucción de estructuras y fabricación o recreación de elementos muebles y de sus funciones (como parte de la arqueología experimental) y una información visual, didáctica y lúdica, guían la creación de pequeños museos locales, organización de exposiciones temporales, Vídeos con imágenes virtuales y breves pero ilustrados catálogos, como fórmulas para divulgar un fragmento de la historia más alejada e inculcar a las nuevas generaciones el respeto por los yacimientos y la atracción por el pasado. Esta política, en que maquetas y reconstrucciones ideales del ambiente permiten la integración del conjunto de datos, está unida a parques arqueológicos o centros histórico-naturales con el fin de conservar "in situ" los restos y hacer más comprensibles los modos de vida en un segmento de tiempo y espacio. A su vez, reconstrucción y recreación a escala más o menos efímera, son una escuela de comprobaciones en la línea de la Etnoarqueología y de la Arqueología Experimental: fuentes de modelos para resolver el alzado y morfología de estructuras, potenciar ideas para verificar manufacturas y usos y cuantificar capacidad de viviendas y almacenaje, horas de trabajo en tumbas, sepelios y ajuares... e incluso la productividad de plantas y animales, siempre en términos de economía y tecnología primitiva.

El alcance de la arqueología experimental es un hecho, en especial en la técnica y función de implementos. El auge y la amplitud de miras están asegurados en un futuro inmediato.

\section{Limitaciones y Medios}

El dinero, obviamente, es una de las mayores cortapisas en proyectos que requieren una enorme inversión, pero también actúan de barreras 
las propias Autonomías, bien por su política hacia la Arqueología en general o por ceñir la investigación a la demarcación autonómica. Las poblaciones del pasado no sabían de límites administrativos e históricamente el espacio a investigar (en ocasiones el área de captación de recursos o la amplitud de un yacimiento en concreto) pertenece a dos o más autonomías e incluso a distinto país. Estas circunstancias derivan en localismos y fragmentan objetivos, además de marcar cierto subjetivismo y énfasis en la autoctonía u obligar al compromiso de resultados a muy corto plazo. Sí es bueno reconocer que Inventarios y Cartas Arqueológicas (más a escala extensiva que intensiva), la mejora cartográfica y la fotografía áerea, así como el uso del GPS para las referencias de situación, son enormemente beneficiosos para la documentación del espacio y su ocupación humana.

A nivel de formación (pese a las ventajas aparentes de elegir un itinerario de disciplinas complementarias) se ha reducido el tiempo y se tiende a la diversidad más que a la formación integrada (es de esperar que se aprueben Títulaciones específicas en Prehistoria o que se dediquen a estudios interdisciplinares cursos de postgrado). Dispersión de medios, burocracia y esfuerzo en gestión y coordinación son cargas añadidas. En cualquier caso, los objetivos aquí planteados no dejan de ser desiderata porque el conocimiento de nuestro pasado prehistórico es muy desigual y son muchas las lagunas sea a nivel geográfico o temporal. La prueba está en que pese a la atención que hoy ponen ciertas editoriales (Crítica, Akal, Síntesis...) en la traducción de las orientaciones más punteras o en obras escritas por los prehistoriadores españoles, y en la multiplicidad de publicaciones y foros científicos, adolecemos de libros de divulgación, síntesis y manuales que reflejen los nuevos alcances. Todavía sigue privando la visión material y las particularidades más que la generalización y la integración cultural.

La informática, programas múltiples y procesamiento de datos e imágenes, son realidad ilimitada. Lupa binocular y microscopio electónico para reconocimiento de huellas de uso o de ciertas particularides materiales, técnicas de lámina delgada... forman parte de los medios disponibles a nivel de equipamiento de un Departamento de Prehistoria, pero los análisis geológicos y edafológicos, los componentes materiales o la analítica más sofisticada, incluidos los métodos de prospección, son, salvo contadas excepciones, del dominio de Ciencias y con más frecuencia de la deseable aparecen como apéndices al final de las $\mathrm{Me}$ morias. Por esta razón, las referencias a investigadores españoles expertos en $\mathrm{C}_{14}$, análisis metalúrgicos, cerámológicos o al estudio de fauna 


\section{¿Hacia dónde camina la Prehistoria española?}

y flora, análisis de restos antropológicos (incluidos los cremados)... son conocidas por todos. El C.S.I.C., el Instituto de Patrimonio Historico, a nivel nacional y determinados Departamentos de Universidades cuentan ya con expertos y medios para TL, radiocarbono, microscopía electrónica de barrido, espectrometría por fluorescencia, Rayos X, emisióm y absorción atómica etc. y existen grupos de trabajo abiertos a intensificar la investigación aplicada a Prehistórica, pero falta todavía un estrecho y fluido diálogo sobre lo que quieren los prehistoriadores y lo que pueden ofrecer determinados equipos humanos y técnicos para satisfacer o potenciar registros y análisis ${ }^{7}$. En el futuro, sea en cada autonomía, o anexos a determinadas universidades, habrán de crearse Centros o Institutos de investigación y análisis al servicio de la Prehistoria/Arqueología en donde bancos de datos, en espera de su puesta en valor, infraestructura y recursos humanos estarán dedicados a la interpretación de muestras o de registros de campo.

\section{Perspectivas de futuro}

Tan ambiciosas metas exigen Proyectos bien diseñados y dotados, dentro de programas amplios y planificados a medio y largo plazo. La excavación de un yacimiento como tal será obsoleta y se tenderá a sacar mejor partido de esfuerzos y dineros seleccionando objetivos con el fin de rellenar lagunas y responder a planteamientos concretos dentro de un marco general.

Un equipo interdisciplinar en la doble línea de prehistoriadores y científicos extraerá directamente del campo los datos que interesan a los análisis de unos objetivos programados. Será una especie de regresión a los años pioneros de la Prehistoria cuando paleontólogos, geólogos e historiadores estaban compremetidos en la misma singladura, sólo que, pasado más de un siglo, el punto de partida y los fines son más ambiciosos y complejos que en los balbuceos de la disciplina.

Se partirá del Inventario autonómico cada vez más completo y documentado. Mediante la detección de anomalías del subsuelo - sea por magnetómetros u otras técnicas cada vez más perfeccionadas, incluidas las posibilidades fotográficas - se conocerá previamente intensidad, extensión y localización de la huella humana en el terreno. Las nuevos métodos atenderán la selección de las áreas o sectores a excavar para verificar o rechazar las hipótesis, comprobar las lecturas y registrar "in situ» evidencias significativas, incluida la recogida de muestras con técnicas cada vez más superadas, fiables y no destructivas. 


\section{M. ${ }^{a}$ Rosario Lucas Pellicer}

Los objetivos se fijarán en aspectos particularizados o globales, y la publicación conjunta interrelacionará, sin discriminación, las diversas variables que confieren su auténtica dimensión a la vida humana, y la imaginación contribuirá a formular nuevas cuestiones. Entre los objetivos, y como medio para rentabilizar cultural y socialmente los esfuerzos, no se marginará la buena divulgación, parte inherente a la Educación futura.

La conservación del espacio será otro fin ineludible, dando preferencia a la protección, reconstrución y simulación de estructuras para verificar conclusiones y extraer nuevos conocimientos y modelos. La vegetación relicta será potenciada y también se intentará recrear el antiguo paisaje.

Aparte de paliar las deficiencias esbozadas y reorientar enfoques, métodos y análisis, la investigación incidirá en explicar y comprender la heterogeneidad cultural de un paisaje tan diversificado como el nuestro y es previsible que aumente la presencia de equipos extranjeros y las subvenciones no oficiales.

En un siglo se ha recorrido un largo camino y el futuro promete ser todavía más cambiante. En cualquier caso, ganará la visión del hombre en sus circunstancias del pasado - una especie de Antropología Prehistórica- y los equipos con nuevas tecnologías enriquecerán las observaciones. Aunque, sea cual sea la corriente teórica, los datos arqueológicos como evidencia de los acontecimientos, seguirán siendo la mejor fuente para hacer Prehistoria.

Unas últimas palabras sobre otra forma de hacer y difundir la historia de las poblaciones ágrafas o con exiguas referencias textuales. Empezamos y cerramos estas líneas con optimismo: ¿Se inventarán técnicas para registrar las voces del pasado?. Lo ignoramos pero hay algo seguro: los propios prehistoriadores o los amantes de esta etapa histórica, como un medio más de contrastar simulaciones, se encargarán de «novelar» fragmentos del pasado. La imaginación llegará a donde no puede llegar una Historia carente de fuentes escritas.

\section{Notas}

1 Vide como ejemplo de síntesis: CASTRo, P. V., Lull, V. y Mico, C. (1996): Cronología de la Prehistoria Reciente de la Península Ibérica y Baleares. Oxford. BAR. I.S.

2 A principios del próximo año funcionará uno de estos aparatos en el Laboratorio Nacional de Aceleradores de Sevilla y en la Universidad Autónoma de Madrid se está procediendo a la instalación del equipo recientemente adquirido. 


\section{¿Hacia dónde camina la Prehistoria española?}

3 Para un desarrollo amplio de estos conceptos Vide Capítulo 6 de la obra: RENFrew, C y BAHN, P. (1993): Arqueología. Teoría, Métodos y Prácticas (1993), Ed. Akal, Madrid. Pese a los años (versión original, 1991) es una de las mejores síntesis sobre las orientaciones en la investigación prehistórica.

4 FERnÁNDEZ MARTINEZ, V. (1994): “Etnoarqueología: una guía de métodos y aplicaciones". Rev. de Dialectología y Tradiciones Populares XLIX, 137-169.

5 BAENA, J. (1997): "Arqueología Experimental, algo más que un juego". Bol. de Arqueología Experimental 1, 4-5, UAM.

6 Vide como monografia de conjunto: BAENA, J., BLASCO, C. y QUESADA, F. (Ed.) (1997): “Los S.I.G y el análisis espacial en Arqueología». Madrid, UAM.

7 Como ejemplo de avances sobre esta relación, la Universidad Autónoma de Madrid, a través del SIDI, canaliza los análisis de la investigación arqueológica hacia determinados Departamentos científicos e incluso los días 23 y 25 de septiemre se han realizado unas jornadas sobre "Aplicaciones industriales de grandes instalaciones científicas" con invitación expresa a prehistoriadores. 